\title{
Dear Reader
}

\section{Bob Kleinmann ${ }^{1}$}

Published online: 11 November 2021

(c) Springer-Verlag GmbH Germany, part of Springer Nature 2021

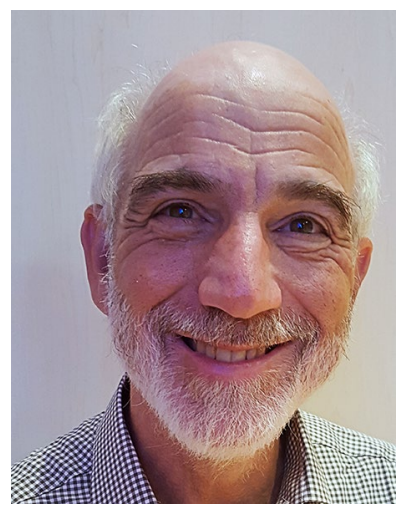

Dear Reader,

I want to start off by warning you all about a scam, since I only recently was able to stop a friend from potentially becoming a victim. After you publish a paper, it is now fairly common to get an email praising the paper from one or more individuals and inviting you to submit a related paper for publication in their Open Access journal or book. You should know that these individuals do not discriminate; they send a similar, seemingly personalized form letter to every author they find. In fact, I always seem to get at last one such request every time I publish one of these columns praising my "very interesting paper titled Dear Reader," and asking me to prepare and submit a similar paper for them. They don't mention that there is a sizable fee for publishing an Open Access paper and that the author is responsible for paying that fee.

Of course, when the 'paper' is only a short column like this one, it is obvious that this is a scam, but if it is paper that you are particularly proud of, it is easy to see how someone might fall victim to such a ploy. I do not mean to suggest that all Open Access journals are scams, but the reputable ones do not solicit papers in this manner. Nearly all Open Access

Bob Kleinmann

Editor@MWEN.info; robert.kleinmann@hdrinc.com

1 HDR, Inc., Pittsburgh, USA

journals require that the authors pay a fee; this is reasonable because they do not collect fees when readers download the papers. Mine Water and the Environment is a hybrid journal, which means that the authors get to decide whether they are willing and able to pay for Open Access (and the associated increased readership) when and if the paper has been accepted for publication. There is no pressure to choose the Open Access option, and if you don't, there is no fee of any sort for publishing a paper in this journal, and your paper can still be downloaded for free by all IMWA members and other subscribers.

Observant repeat authors might also notice a change in the language they must agree to at the same time they decide about whether or not to select Open Access. Instead of being asked to assign the copyright for the paper to the journal and Springer Nature, authors will now be asked to assign us a license to publish the paper. This means that the authors retain full copyright for their work.

Regarding this issue, the first few papers are again responses to our request to our more senior IMWA members for their personal insights and perspectives about IMWA and the various areas of mine water research in which they have been involved. You can expect to see a couple more of these in our March 2022 issue.

This issue contains an interesting array of mine water research topics, with contributions from ten or more countries. Unfortunately, we must end this issue with the obituaries of two of IMWA's founding members, written by our now sole surviving founder, Rafael Fernández-Rubio, who has promised that he will remain actively involved with IMWA for as many years as fate allows him to be with us.

But now, let's celebrate-what a great year 2021 has been for this journal! We celebrated our 40th year of publication gloriously, with two special issues, some beautiful cover images (with more to come in 2022), and at least $25 \%$ more pages published this year than ever before. Although the pandemic might have limited your ability to pursue all of your normal activities this past year, at least we gave you plenty to read. 
This of course meant more work for all of our editors, abstract translators, and reviewers. I honestly believe that we do a pretty good job, considering that we are all volunteers. I know that the authors appreciate all of the work that we do to improve their papers because many of them send me emails letting me know this, but I typically only get involved when the papers are ready for final editing and polishing. So, on behalf of all this journal's subscribers, I'd like to first thank all of the editors who work on the papers before that time, including sending the papers out for review: Mostafa Benzaazoua, Melanie Blanchette, Robert Bowell, Carlos Ruis Cánovas, Dong Donglin, Dong Shuning, Rafael FernándezRubio, Grant Douglas, Rodrigo Jr Embile, Braden Hanna, Gyözö Jordan, Candace L. Kairies-Beatty, Jeff Langmann, Li Peiyue, Li Wenping, Ann Maest, Steven Meyerhoff, Len Murray, Robert Nairn, Benoit Plante, Dyllon Randall, Pierre Rouseau, Abhay Kumar Singh, Gideon Steyl, Christie Terrell, Purushotham Tukkarja, Vishwananth Ravi Kumar Vadapalli, Teresa Valente, Robert Van Hille, John Douglas Waterhouse, Wu Qiang, Kendra Zamzow, and Wanfang Zhou, Christian Wolkersdorfer (who, in addition to serving as IMWA's president, is this journal's Managing Editor) and of course, the fantastic Anne Weber, who coordinates the efforts of all of these wonderful folks.

Thanks also to our volunteer abstract translators: Edgardo Donati, Jörn Geletneky, Helmuth Landsmann, Joscha Opitz,
Walter Pohl, Martin Schultze, Wilfried Uhlmann, Kai-Uwe Ulrich, Wang Changshen, and Josepha Zielke, who coordinates the abstract translation process.

I also thank the Springer Nature staff who we depend on to keep us on track and to publish and distribute this journal. And of course, we thank our authors (without them there would be no journal), our reviewers (who I will give due credit to in our next issue), and you, our readers for your continued interest and feedback.

By the time you are reading this, we will all be wrapping up 2021 and starting to plan for 2022. And hopefully you will be getting together with your extended families to celebrate whatever holidays you traditionally do in December. Personally, I like to celebrate all of them! On behalf of the entire editorial staff, I wish you happy holidays and a wonderful 2022.

Best Regards,

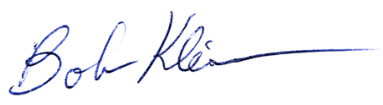

Bob Kleinmann, PhD; Editor-in-Chief editor@MWEN.info 